\title{
Clinical Outcome of Patients with Lymph Node-Positive Prostate Cancer following Radical Prostatectomy and Extended Sentinel Lymph Node Dissection
}

\author{
Alexander Muck ${ }^{\mathrm{a}}$ Christian Langesberg $^{\mathrm{b}}$ Michael Mugler ${ }^{\mathrm{c}}$ \\ Jörg Rahnenführer ${ }^{b}$ Bernd Wullich $^{d}$ Wolfgang Schafhauser ${ }^{a}$ \\ ${ }^{a}$ Department of Urology, Klinikum Fichtelgebirge, Marktredwitz, ${ }^{b}$ Faculty of Statistics, TU Dortmund University, \\ Dortmund, 'Partnerschaft Pathologie Hof, Hof, and ${ }^{\mathrm{d}}$ Department of Urology, Friedrich Alexander University of \\ Erlangen-Nuremberg, Erlangen, Germany
}

\section{Key Words \\ Lymph node metastasis - Outcome · Prostate cancer . \\ Prostatectomy · Sentinel lymph node dissection}

\begin{abstract}
Objective: This study sought to evaluate the clinical outcome after extended sentinel lymph node dissection (eSLND) and radical retropubic prostatectomy (RRP) in patients with clinically localized prostate cancer (PCa). Subjects and Methods: From August 2002 until February 2011, a total of 819 patients with clinically localized $\mathrm{PCa}$, confirmed by biopsy, were treated with RRP plus eSLND. Biochemical recurrencefree survival (RFS), cancer-specific survival (CSS), and overall survival (OS) were assessed with Kaplan-Meier curves. Various histopathological parameters were analyzed by univariate and multivariate analysis. Results: The mean follow-up was 5.3 years. Lymph node (LN) metastases occurred in 140 patients. We removed an average of $10.9 \mathrm{LNs}$ via eSLND from patients with pN1 PCa. Postoperatively, 121 pN1 patients temporarily received adjuvant androgen deprivation therapy. The mean survival periods for RFS, RFS after secondary treatment, CSS, and OS were 4.7, 7.0, 8.8, and 8.1 years, respectively. The cancer-specific death rate of the $140 \mathrm{pN} 1 \mathrm{pa}-$
\end{abstract}

tients was $13.6 \%$. RFS, CSS, and OS were significantly correlated with pathological margin status, LN density, the total diameter of evident metastases, and membership in the subgroup 'micrometastases only'. Conclusion: Despite the presence of $L N$ metastases, patients with a low nodal tumor burden demonstrate a remarkable clinical outcome after undergoing eSLND and RRP, thus suggesting a potential curative therapeutic approach.

(c) 2014 S. Karger AG, Basel

\section{Introduction}

For patients with clinically localized prostate cancer (PCa), the absence of lymph node involvement (LNI) improves their prognosis for prostate-specific antigen (PSA) recurrence-free survival (RFS) and cancer-specific survival (CSS) [1]. At present, pelvic lymph node dissection (PLND) is considered the optimal staging procedure and

The present study was performed in fulfillment of the requirements for obtaining the degree of Dr. med. dent. at the Friedrich Alexander University of Erlangen-Nuremberg (FAU).

\begin{tabular}{ll}
\hline KARGER 125/\% & $\begin{array}{l}\text { @ 2014 S. Karger AG, Basel } \\
0042-1138 / 14 / 0943-0296 \$ 39.50 / 0 \quad \text { Open carcess }\end{array}$ \\
$\begin{array}{l}\text { E-Mail karger@karger.com } \\
\text { www.karger.com/uin }\end{array}$ & $\begin{array}{l}\text { Thisis an Open Access article licensed under the terms of the } \\
\text { Creative Commons Attribution-NonCommercial 3.0 Un- } \\
\text { ported license (CC BY-NC) (www.karger.com/OA-license), } \\
\text { applicable to the online version of the article only. Distribu- } \\
\text { tion permitted for non-commercial purposes only. }\end{array}$
\end{tabular}

Wolfgang Schafhause

Department of Urology, Klinikum Fichtelgebirge

Schillerhain 1-8

DE-95615 Marktredwitz (Germany)

E-Mail w.schafhauser@googlemail.com 
method of choice for detecting LNI [2]. Extended PLND (ePLND) and gamma probe-guided sentinel lymph node dissection (SLND), which is easier to perform and more accurate, increase the detection rate of LNI compared with standard PLND and limited lymphadenectomy (IPLND) [3, 4], which fail to detect a significant number of lymph node (LN) metastases [5]. Furthermore, ePLND and SLND may significantly improve RFS by removing an increased number of remote positive LNs and occult micrometastases [6]. Some authors have reported a therapeutic effect of ePLND only in high-risk PCa patients [7-9], whereas others have observed this effect in LNpositive and LN-negative PCa patients alike $[7,10,11]$. In addition, other studies have failed to identify the therapeutic value of PLND $[12,13]$. Considering all adjuvant and secondary treatment procedures, the current study sought to evaluate the clinical outcome of $\mathrm{pN} 1$ patients presenting with clinically localized PCa following radical retropubic prostatectomy (RRP) and open bilateral extended SLND (eSLND).

\section{Subjects and Methods}

\section{Study Design}

A retrospective analysis of clinical follow-up data was performed in a total of 819 consecutive patients with clinically localized $\mathrm{PCa}$, histologically confirmed after rectal examination, abdominal and pelvic computerized tomography, bone scintigraphy, and chest X-ray. At the urological clinic of the Prostatazentrum Hochfranken-Fichtelgebirge, these patients underwent RRP in combination with open bilateral eSLND. A prospective analysis of perioperative data was registered in the data bank of the prostate center by an assigned study nurse.

\section{Technique of Lymphadenectomy and Histopathological}

\section{Evaluation}

In 1999, Wawroschek first described the technique of SLND that we performed in this study $[3,14]$. After injecting technetium$99 \mathrm{~m}$ nanocolloid, scintigraphic imaging was conducted. During surgery, radioactive marked pelvic sentinel LNs (SLNs) were identified via gamma probe and resected. In addition to the removal all of marked SLNs from the presacrum to the common iliac artery (SLND), LNs were routinely and fully dissected via standard PLND in the obturator fossa and along the external iliac vein. In addition, enlarged LNs on palpation were dissected by means of eSLND at the external, internal, and common iliac artery as well as in the pararectal region.

Serial sections, with 32 step intersections at most to detect micrometastases $(<2 \mathrm{~mm})$, and immunohistochemical samples with 2 step intersections (anti-cytokeratin AE1/3 Zytomed-Systems ${ }^{\circledR}$ using on-slide positive controls) at most were performed in all SLNs to identify isolated tumor cells ( $\mathrm{i}+/-$ ). Non-SLNs were examined as usual with 2 step intersections. This histological examination method was carried out by 4 histopathologists of one single institution.

\section{Clinical Outcome}

The patients were treated as outpatients mainly by regional urological specialists during the preoperative and postoperative phases. Routine follow-up included digital rectal examination, serum PSA evaluation, and sonographic examination. Additionally, transrectal ultrasound, computerized tomography, magnetic resonance imaging, skeletal scintigraphy, and positron emission tomography were optional diagnostic procedures if there was evidence of systemic progression or an elevated PSA level. The primary endpoint of the study remained PSA recurrence, which was defined as a serum PSA elevation $>0.2 \mathrm{ng} / \mathrm{ml}$ after an initial postoperative drop of $<0.07 \mathrm{ng} / \mathrm{ml}$. The time period from RRP and eSLND until PSA recurrence was defined as biochemical RFS. Complete response (CR), partial response (PR), stable disease (SD), progression, and mortality were also investigated. CSS and overall survival (OS) were determined based on the time of operation until PCa-related death or death due to other causes.

The complete follow-up data were recorded by the original author via standardized evaluation forms, sent to the attending urologists, and registered in the prostate center's data bank. In cases of missing or unclear data, we contacted physicians, patients, relatives, or the respective registration office.

\section{Statistical Analysis}

Mean values, standard deviations, median values, ranges, and incidence rates were determined via descriptive analysis. KaplanMeier curves were used to determine RFS, CSS, and OS. The event dates of two patient groups were compared via log-rank tests. Univariate and multivariate Cox regression analysis was used to examine the effect of various histological variables on RFS, CSS, and OS. For multivariate analyses, an initial multivariate model was adapted to 8 preselected parameters before variables were selected.

SPSS software was used for all analyses, with $\mathrm{p}<0.05$ indicating statistical significance.

\section{Patients}

This study included 819 consecutive patients with clinically localized, biopsy-proven PCa who underwent RRP in combination with eSLND from August 2002 until February 2011. The period of followup lasted from August 2002 until March 30, 2013. Figure 1 shows the distribution of the patients according to therapy and clinical response. Postoperatively, 117 (83.6\%) of the 140 node-positive patients were treated with androgen deprivation (AD) for up to 24 months (4 patients up to 36 months). In regard to recurrence, secondary therapy was delivered to 77 patients (55\%). Thereby, $22.1 \%$ of the patients underwent $\mathrm{AD}, 9.3 \%$ radiotherapy (RT), $2.9 \%$ chemotherapy, $12.1 \%$ combined AD and RT, $5.0 \%$ combined AD and chemotherapy, and $3.6 \%$ a combination of $\mathrm{AD}, \mathrm{RT}$, and chemotherapy.

\section{Data Collection}

For the evaluation of patient records, relevant parameters were selected and examined in regard to the intended data analysis. This evaluation included preoperative data, surgical treatment, and, finally, postoperative follow-up data. The tumor burden of LNI per patient was determined according to the following variables: (1) the total number of nonaffected and affected SLN as well as the equivalent number of non-SLN; (2) the total diameter (in millimeters) of affected SLN and non-SLN metastases; (3) the presence of macro- and/or micrometastases (micrometastasis defined as $>0.2$ and $\leq 2 \mathrm{~mm}$ ) [15]. 


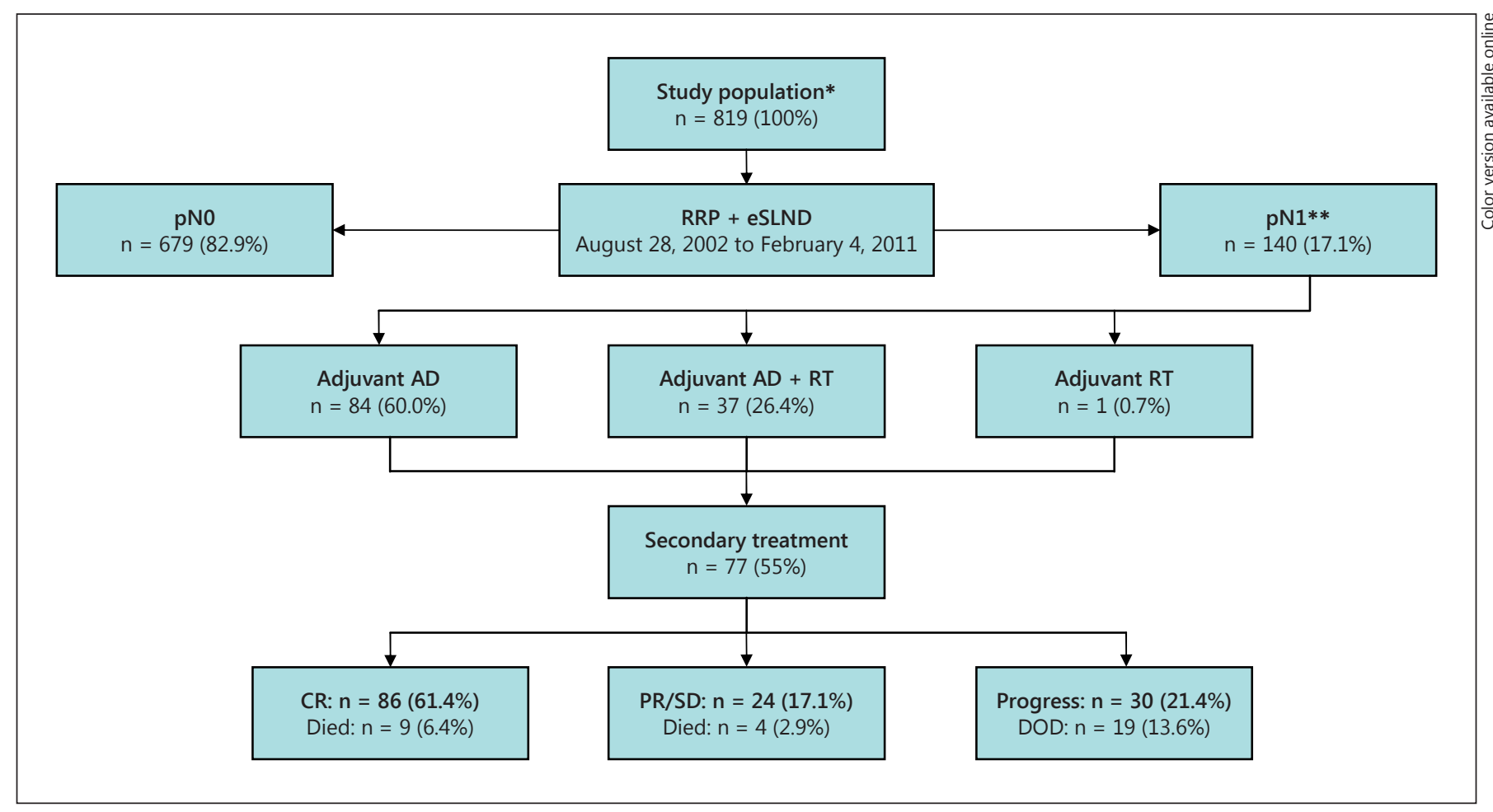

Fig. 1. Distribution of patients depending on the delivered therapies and clinical response. DOD $=$ Dead of disease (PCa). Preoperative neoadjuvant AD: ${ }^{*} \mathrm{n}=341(41.6 \%) ;{ }^{* *} \mathrm{n}=81(57.9 \%)$.

\section{Results}

\section{Characteristics of the Patients and LN Metastases}

The mean age of the pN1 study population was 67.1 years at the time of surgery. After grouping the various risk values for LNI using Partin tables (2001 version), the probability of developing LN metastasis appeared to be underestimated, especially in the groups with a median value above $5 \%$. Preoperative AD was often selected by patients and attending urologists while deciding on and/ or waiting for the operation (fig. 1). According to the follow-up data of table 1, the mean follow-up period lasted 5 years. In the pN1 group, 39\% of the patients suffered PSA recurrence by the time of the final follow-up, and PCa-related mortality amounted to $13.6 \%$ in this group.

In 9 patients (6.4\%), SLNs could not be identified via technetium-99 nanocolloid; $7.9 \%$ of the patients did not show tumor-positive SLNs histopathologically. In these cases, only non-SLNs were affected. Thus, via eSLND (table 2), 184 SLN metastases, with a mean of 1.5 SLNs per patient (range: 1-6), were detected in 120 patients. A total of 20 patients presented only with positive non-SLNs; 27 additional patients showed tumor disease in SLNs as well as non-SLNs. Tumor involvement of SLNs exclusively occurred in 93 patients $(66.4 \%)$. In $82.1 \%$ of the patients, positive LNs would have been missed if dissection had only taken place in the region corresponding to conventional lPLND.

Upon examination of LNI, micrometastases were exclusively detected in $37.9 \%$ of the patients, and in combination with macrometastases in $15.7 \%$ (table 2). LN density (LND) was defined as percentage of positive LNs in relation to the total number of analyzed LNs; LND was $\leq 20 \%$ in $62.9 \%$ of the patients.

\section{Stratification of Survival: RFS, CSS, and OS}

The distribution of the patients according to clinical outcome after all forms of secondary therapy is presented in figure 1. At the time of the final follow-up, $108 \mathrm{pN} 1$ patients out of the 140 patients $(77.1 \%)$ remained alive. Nineteen patients (13.6\%) out of the 32 deceased patients died of progressive metastatic PCa. Mean RFS, RFS after secondary therapy, CSS, and OS for the $\mathrm{pN} 1$ study population were 4.7 (95\% CI: 4.1-5.3), 7.0 (95\% CI: 6.4-7.5), 8.8 (95\% CI: 8.3-9.4), and 8.1 years (95\% CI: 7.5-8.7), respectively. 
Table 1. Patient characteristics in the pN1 category

\begin{tabular}{|c|c|}
\hline Patient characteristics & $\mathrm{pN} 1(\mathrm{n}=140 ; 17.1 \%)$ \\
\hline \multicolumn{2}{|l|}{ Preoperative parameters } \\
\hline Age at time of operation, years & $67.1(67.8 ; 63.4-73.0)$ \\
\hline Time of diagnosis until surgery, days & $70.0(54.5 ; 42.0-70.8)$ \\
\hline \multicolumn{2}{|l|}{ Preoperative D'Amico risk group classification } \\
\hline Low risk: iPSA $<10$ and Gleason score $\leq 6$ and $\mathrm{cT} \leq 2 \mathrm{a}$ & $2(1.4)$ \\
\hline Intermediate risk: iPSA $10-20$ or Gleason score $=7$ or $c \mathrm{~T}=2 \mathrm{~b}$ or $2 \mathrm{c}$ & $49(35.0)$ \\
\hline High risk: iPSA $\geq 20$ or Gleason score $\geq 8$ or $\mathrm{cT}>2 \mathrm{c}$ & $89(63.6)$ \\
\hline Preoperative risk of LN metastases by Partin, \% & $20.6(14 ; 8-38)$ \\
\hline \multicolumn{2}{|l|}{ Partin LN risk group, $\mathrm{n}$ (\% of risk group) } \\
\hline $0 \%$ & $1(0.6)$ \\
\hline$>0$ and $\leq 5 \%$ & $22(6.4)$ \\
\hline$>5$ and $\leq 10 \%$ & $22(30.6)$ \\
\hline$>10$ and $\leq 30 \%$ & $38(31.7)$ \\
\hline$>30 \%$ & $57(55.3)$ \\
\hline \multicolumn{2}{|l|}{ Prostatectomy parameters } \\
\hline \multicolumn{2}{|l|}{ Pathological stage } \\
\hline pT2 & $16(11.4)$ \\
\hline pT3a & $39(27.9)$ \\
\hline pT3b & $66(47.1)$ \\
\hline pT4 & $19(13.6)$ \\
\hline \multicolumn{2}{|l|}{ Gleason score } \\
\hline$\leq 6$ & $2(1.4)$ \\
\hline 7 & $66(47.1)$ \\
\hline $8-10$ & $72(51.4)$ \\
\hline \multicolumn{2}{|l|}{ State of marginal section } \\
\hline $\mathrm{pR} 0$ & $76(54.3)$ \\
\hline $\mathrm{pR} 1$ & $64(45.7)$ \\
\hline \multicolumn{2}{|l|}{ Follow-up data } \\
\hline Follow-up duration, years & $5.0(4.8 ; 2.9-6.9)$ \\
\hline Patients with PSA recurrence at last follow-up & $54(38.6)$ \\
\hline Carcinoma-specific mortality at last follow-up & $19(13.6)$ \\
\hline Overall mortality at last follow-up & $32(22.9)$ \\
\hline
\end{tabular}

Values denote means with medians and IQR in parentheses or numbers of patients with percentages in parentheses unless specified otherwise. iPSA = Initial PSA.

The results of the univariate analysis of $\mathrm{pN} 1$ patients (Kaplan-Meier curves, log-rank test) are presented in table 3. In regard to histopathological characteristics of the primary tumor, $\mathrm{pT}$ stage relating to RFS and Gleason score relating to CSS and OS significantly affected the outcome of the study population. The pathological state of the intersection margin (pR), as the most important factor, significantly impacted all study endpoints. Thus, pR0-resected patients presented with longer RFS, a significantly longer RFS after secondary therapy, and improved CSS as well as OS than patients with pR1 status.

Outcome of Extended Sentinel Lymph Node Dissection
Concerning quantitative and qualitative variables of the LN metastases, the number of LN metastases, LND, the mere presence of micrometastases, and the total diameter of all LN metastases were relevant. Patients with a lower metastatic burden presented with a significantly improved outcome. Furthermore, patients with a total diameter of all LN metastases $\leq 3 \mathrm{~mm}$ demonstrated an advantage in RFS, RFS after secondary therapy, CSS, and OS. The most significant factor, however, was the mere presence of micrometastases, which was associated with improved RFS, RFS after secondary therapy, CSS, and OS (Kaplan-Meier curves; fig. 2). 
Table 2. Data relating to lymphadenectomy

\begin{tabular}{lc}
\hline Patients with removed and microscopically evaluated LNs & $140(100)$ \\
\hline Number of removed and microscopically evaluated LNs (non-SLNs and SLNs) & $10.9(9 ; 3-30)$ \\
Number of positive LNs (non-SLNs and SLNs) & $2.1(1.0 ; 1-11)$ \\
\hline Patients with removed and microscopically evaluated SLNs & $131(93.6)$ \\
Number of removed and microscopically evaluated SLNs & $3.7(3.0 ; 1-11)$ \\
Patients with positive SLNs & $120(85.7)$ \\
Number of positive SLNs & $1.5(1.0 ; 1-6)$ \\
\hline Number of patients with LN metastases & $93(66.4)$ \\
$\quad$ Merely of SLNs & $27(19.3)$ \\
Of SLNs and non-SLNs & $20(14.3)$ \\
$\quad$ Merely of non-SLNs & $25(17.9)$ \\
\hline Number of patients with LN metastases in the following regions & $85(60.7)$ \\
$\quad$ Exclusively in the obturator fossa & $140(100)$ \\
Exclusively externally to the obturator fossa & $65(46.4)$ \\
\hline Patients with macro- and/or micrometastases & $22(15.7)$ \\
$\quad$ Patients with macrometastases & $53(37.9)$ \\
$\quad$ Patients with macro- and micrometastases & $9.1(3.6 ; 0.2-110)$ \\
\hline Patients with merely micrometastases (0.2-2.0 mm) & \\
\hline Total diameter of all LN metastases, mm & \\
\hline Values denote means with medians and IQR in parentheses per patient or numbers of patients with percent-
\end{tabular}

Table 3. Univariate analysis of the selected histopathological risk factors ( $\mathrm{pN} 1, \mathrm{n}=140$ )

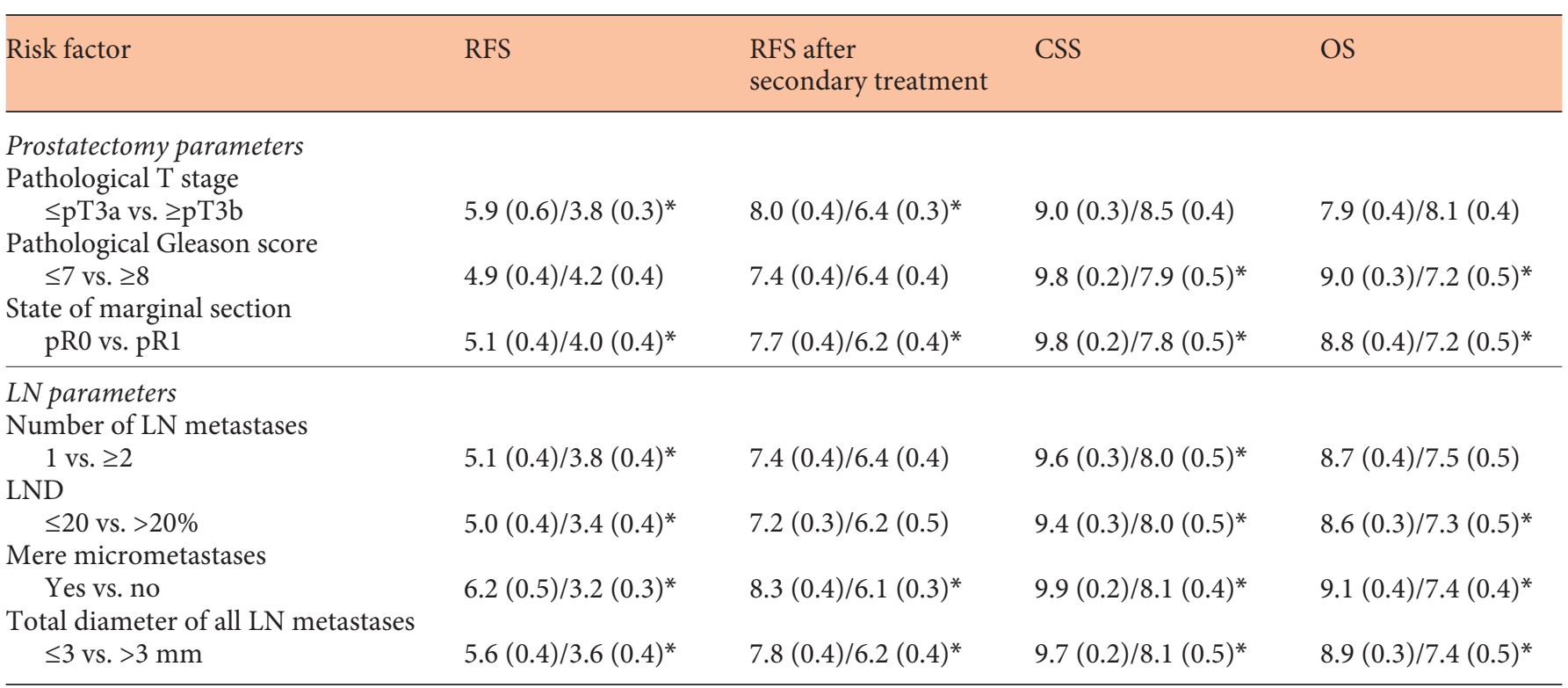

Values denote mean survival in years with SE in parentheses. ${ }^{*} \mathrm{p}<0.05$ (significant). 


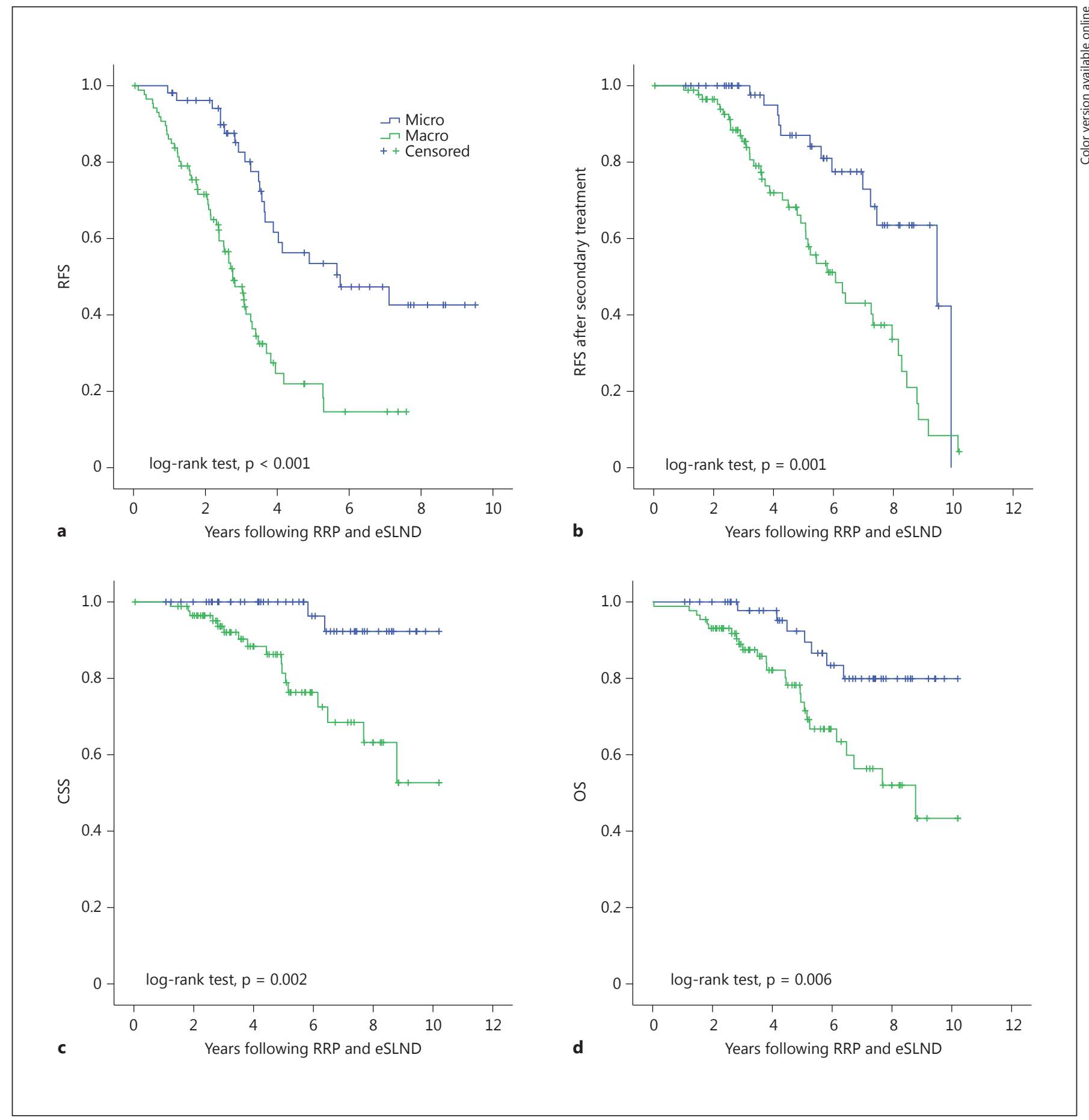

Fig. 2. Kaplan-Meier curves of RFS (a), RFS after secondary treatment (b), CSS (c), and OS (d). Upper lines (blue; colors refer to the online version only): patients with mere micrometastases (53 patients). Lower lines (green): patients with macro- or macro- plus micrometastases (87 patients). 
Table 4. Significant factors in the multivariate analyses of the selected histopathological risk factors $(\mathrm{pN} 1, \mathrm{n}=$ 140)

\begin{tabular}{|c|c|c|c|c|}
\hline Risk factor & Level of reference & $\mathrm{p}$ value & Hazard ratio & $95 \% \mathrm{CI}$ \\
\hline \multicolumn{5}{|l|}{ RFS } \\
\hline Mere micrometastases & no vs. yes & $0.000^{*}$ & 2.6 & $1.6-4.5$ \\
\hline iPSA $(\log )$ & & $0.022^{*}$ & 1.9 & $1.1-3.3$ \\
\hline Pathological T stage & $\leq$ pT3a vs. $\geq$ pT3b & 0.081 & 1.6 & $0.9-2.7$ \\
\hline \multicolumn{5}{|l|}{ RFS after secondary treatment } \\
\hline Mere micrometastases & no vs. yes & $0.003^{*}$ & 2.6 & $1.4-4.9$ \\
\hline State of marginal section & pR1 vs. pR0 & $0.040^{\star}$ & 1.8 & $1.0-3.1$ \\
\hline \multicolumn{5}{|l|}{ CSS } \\
\hline State of marginal section & pR1 vs. pR0 & $0.028^{*}$ & 4.2 & $1.2-14.8$ \\
\hline Pathological Gleason score & $\geq 8$ vs. $\leq 7$ & $0.049^{*}$ & 3.6 & $1.0-13.0$ \\
\hline Mere micrometastases & no vs. yes & 0.059 & 4.3 & $1.0-19.2$ \\
\hline \multicolumn{5}{|l|}{ OS } \\
\hline Pathological Gleason score & $\geq 8$ vs. $\leq 7$ & $0.022^{*}$ & 2.6 & $1.2-6.0$ \\
\hline Mere micrometastases & no vs. yes & $0.040^{*}$ & 2.5 & $1.0-6.2$ \\
\hline Pathological T stage & $\leq$ pT3a vs. $\geq$ pT3b & $0.048^{*}$ & 0.4 & $0.2-1.0$ \\
\hline State of marginal section & pR1 vs. pR0 & 0.054 & 2.2 & $1.0-5.0$ \\
\hline
\end{tabular}

Initial indicators: state of marginal section, pathological Gleason score, extent of micro-/macrometastases, number of positive LNs (1 vs. $\geq 2$ ), pathological T stage, LND ( $\leq 20$ vs. $>20 \%$ ), and $\log (\mathrm{iPSA}) .{ }^{*} \mathrm{p}<0.05$ (significant). iPSA = Initial PSA.

\section{Multivariate Analysis of Potential Risk Factors}

In the multivariate analysis (Cox regression analysis, table 4) evaluating RFS and OS, one of the most significant prognostic factors was evidence of macro- versus micrometastases. Additionally, a pathological Gleason score $\geq 8$ in CSS and OS was found to be relevant. In addition, the presence of a positive intersection margin presented a disadvantage for $\mathrm{pN} 1$ patients in regard to RFS after secondary treatment and CSS.

Comparison of pNO and pN1 Patients by D'Amico Risk Group Classification and Postoperative Gleason Score

To examine preoperative parameters regarding their impact on CSS, the D'Amico risk group classification is often used clinically before surgery. However, the postoperatively obtained LN status is required to differentiate prognoses concerning CSS in a clinically relevant manner. The high-risk group of pN0 patients showed improved CSS, similar to the low-risk and intermediate-risk groups, compared with $\mathrm{pN} 1$ patients (fig. 3). Moreover, the results shown in figure 3 further support the use of extended lymph dissection, including eSLND. The precise $\mathrm{pN}$ status is required to more accurately predict the postoperative prognosis. Our results also indicate that the
Gleason score serves as a relevant postoperative prognostic factor for sufficient stratification of CSS only in cases with known pN status.

\section{Discussion}

Several studies have demonstrated that characteristics of the primary tumor influence the outcome of $\mathrm{pN} 1 \mathrm{pa}-$ tients $[1,2,10,15-18]$. In this study, besides pathological T stage, the most relevant parameters identified via univariate and multivariate analyses included the pathological state of the intersection margin and pathological Gleason score; both factors significantly affected the outcome of the patient population. In contrast, Boorjian et al. [19] and Palapattu et al. [16] did not observe a correlation between pT stage and outcome in pN1 patients. In agreement with other studies, however, we found that patients with a more differentiated PCa showed an improved survival rate $[15,16,18]$.

The number of removed LNs and LN metastases reflects the accuracy of staging and depends on the individual degree and comprehensive dissection of LNs [15]. In our RRP patients $(\mathrm{n}=819)$, $\mathrm{pN} 1$ patients were identi- 

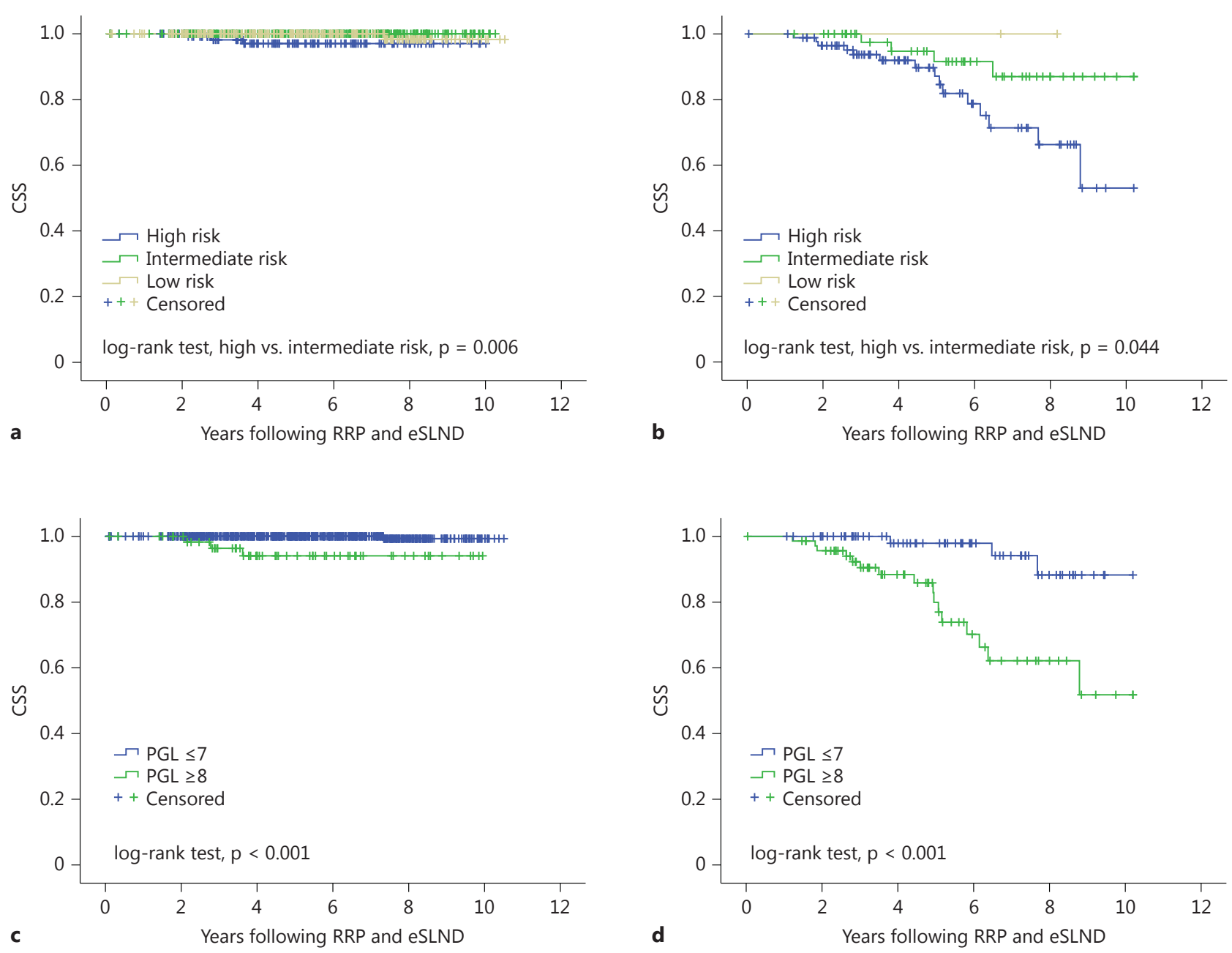

Fig. 3. Kaplan-Meier curves of CSS of $\mathrm{pN0}$ patients (a) and of $\mathrm{pN1}$ patients (b) stratified by D'Amico risk classification, as well as Kaplan-Meier curves of CSS of pN0 patients (c) and of pN1 patients (d) stratified by the pathological Gleason score (PGL) of the surgical tissue ( $\leq 7$ vs. $\geq 8$ ).

fied approximately $2-3$ times more often than would have been expected using the common Partin tables, which had been adjusted using IPLND [20]. Keeping in mind perioperative complications regarding lymphoceles requiring treatment [21], it would probably be helpful to use the recent European nomograms adjusted for ePLND from now on, which are not yet widely used [22]. In our patient population, the number of LN metastases as well as LND served as significant predictors of RFS and CSS, and numerous studies support this conclusion $[1,2,10$, 15-18]. The most significant parameter affecting the outcome of $\mathrm{pN} 1$ patients, as confirmed by univariate and multivariate analyses, was evidence of macrometastases.
Moreover, our results concerning 5-year CCS and 5-year OS were similar to those of Bader et al. [1] and Fleischmann et al. [15] (table 5).

According to previous studies, the method and extent of PLND in LN-positive PCa remain controversial. However, the degree of PLND is significant in two ways. First, accurate staging helps predicting postoperative prognosis and affects the decision to administer adjuvant therapy [23]. Second, a greater number of LN metastases may be removed with curative intent by means of optimized LN extirpation [23]. Any benefit of IPLND is somewhat unlikely, as two-thirds of all affected LNs are missed or appear out of range from the surgical volume of dissection 
Table 5. Literature comparison: impact of surgical volume on outcome in patients with LN metastases undergoing RRP and PLND with or without adjuvant therapy

\begin{tabular}{|c|c|c|c|c|c|c|c|}
\hline Study & Year & $\begin{array}{l}\text { Method of } \\
\text { operation }\end{array}$ & $\begin{array}{l}\text { Total } \\
\text { popu- } \\
\text { lation }\end{array}$ & $\begin{array}{l}\mathrm{pN} 1 \text { cases, } \\
\mathrm{n}(\%)\end{array}$ & Special features & $\begin{array}{l}\text { Average number } \\
\text { of removed LNs } \\
\text { per patient }\end{array}$ & Survival \\
\hline $\begin{array}{l}\text { Bader et al. } \\
{[1]}\end{array}$ & 2003 & $\mathrm{RRP}+\mathrm{ePLND}$ & 367 & $92(25)$ & $\begin{array}{l}\text { no preoperative } \mathrm{AD} \text { or } \mathrm{RT} \text {, no adjuvant } \\
\text { therapy; } \mathrm{PSA}>0.4 \mathrm{ng} / \mathrm{ml}=\mathrm{BCR}\end{array}$ & $21 \mathrm{LN}^{\mathrm{a}} ; 2 \mathrm{~N}+^{\mathrm{a}}$ & $\begin{array}{l}\text { 5-year CSS 74\%; } \\
\text { 5-year CSS }>80 \%{ }^{\mathrm{b}}\end{array}$ \\
\hline $\begin{array}{l}\text { Allaf et al. } \\
\text { [2] }\end{array}$ & 2004 & RRP + ePLND & 2,135 & $71(3.3)$ & $\begin{array}{l}\text { no neoadjuvant } \mathrm{AD} \text {; no adjuvant } \mathrm{AD} \\
\text { or RT; } \mathrm{PSA}>0.2 \mathrm{ng} / \mathrm{ml}=\mathrm{BCR}\end{array}$ & $14.7 \mathrm{LN} ; 1.7 \mathrm{~N}+$ & 5-year RFS 34.4\% \\
\hline $\begin{array}{l}\text { Daneshmand } \\
\text { et al. [10] }\end{array}$ & 2004 & $\begin{array}{l}\text { RRP + bilateral } \\
\text { PLND }\end{array}$ & 1,936 & $235(12.1)$ & $\begin{array}{l}69 \% \text { no neo-/adjuvant therapy; } \\
17 \% \text { postoperative diethylstilbestrol; } \\
14 \% \text { postoperative } \mathrm{AD} / \mathrm{RT} \text { or } \mathrm{AD} \text { at } \\
\text { recurrence; } \mathrm{PSA} \geq 0.05 \mathrm{ng} / \mathrm{ml}=\mathrm{BCR}\end{array}$ & $19 \mathrm{LN}^{\mathrm{a}} ; \mathrm{N}+\mathrm{NA}$ & 5 -year RFS 54\% \\
\hline $\begin{array}{l}\text { Engel et al. } \\
\text { [29] }\end{array}$ & 2010 & RRP + PLND & NA & 688 & $\begin{array}{l}72.1 \% \text { adjuvant } \mathrm{AD} \text { vs. } 27.9 \% \text { no } \\
\text { adjuvant } \mathrm{AD} ; 19.2 \% \text { adjuvant } \mathrm{RT} \text { vs. } \\
80.8 \% \text { no adjuvant } \mathrm{RT} \text {; } \mathrm{BCR}=\mathrm{NA}\end{array}$ & LN: NA; N+: NA & 5-year OS 83.7\% \\
\hline $\begin{array}{l}\text { Fleischmann } \\
\text { et al. [15] }\end{array}$ & 2009 & $\begin{array}{l}\text { RRP + bilateral } \\
\text { ePLND }\end{array}$ & NA & 102 & $\begin{array}{l}\text { No neo-/adjuvant } \mathrm{AD} ; \mathrm{AD} \text { at } \\
\text { progression; } \mathrm{PSA} \geq 0.2 \mathrm{ng} / \mathrm{ml}=\mathrm{BCR}\end{array}$ & $21 \mathrm{LN}^{\mathrm{a}} ; 2 \mathrm{~N}^{\mathrm{a}}$ & $\begin{array}{l}\text { 5-year RFS 28\%; 5-year } \\
\text { CSS 78\%; 5-year OS 75\%; } \\
5 \text {-year CSS/OS } 94 \%^{\mathrm{b}}\end{array}$ \\
\hline $\begin{array}{l}\text { Schumacher } \\
\text { et al. [18] }\end{array}$ & 2008 & RRP + ePLND & 602 & $122(20.3)$ & $\begin{array}{l}50 \% \text { postoperative } \mathrm{AD} \text { vs. } 50 \% \text { no } \\
\text { postoperative } \mathrm{AD} ; 7.4 \% \text { secondary } \\
\text { chemotherapy; } 14.8 \% \text { secondary } \mathrm{RT} \text {; } \\
\mathrm{PSA} \geq 0.2 \mathrm{ng} / \mathrm{ml}=\mathrm{BCR}\end{array}$ & $22 \mathrm{LN}^{\mathrm{a}} ; \mathrm{N}+\mathrm{NA}$ & $\begin{array}{l}5 \text {-year RFS } 13.9 \%^{\mathrm{a}} \text {; } 5 \text {-year } \\
\text { CSS } 84.5 \%^{\mathrm{a}} \text {; } 5 \text {-year OS } \\
83.3 \%^{\mathrm{a}}\end{array}$ \\
\hline Present study & 2014 & RRP + eSLND & 819 & $140(17.1)$ & $\begin{array}{l}12.9 \% \text { no adjuvant therapy; } 60 \% \\
\text { adjuvant } \mathrm{AD} ; 0.7 \% \text { adjuvant } \mathrm{RT} ; 26.4 \% \\
\text { adjuvant } \mathrm{AD}+\mathrm{RT} ; 52.9 \% \text { secondary } \\
\text { therapy; } \mathrm{PSA} \geq 0.2 \mathrm{ng} / \mathrm{ml}=\mathrm{BCR}\end{array}$ & $\begin{array}{l}10.9 \mathrm{LN} ; 2.1 \mathrm{~N}+ \\
1.3 \mathrm{SLN}+99 \mathrm{LN}^{\mathrm{a}} \\
1 \mathrm{~N}+{ }^{\mathrm{a}} ; 1 \mathrm{SLN}+^{\mathrm{a}}\end{array}$ & $\begin{array}{l}5 \text {-year RFS } 35 \% \text {; } 5 \text {-year } \\
\text { CSS } 89 \% \text {; } 5 \text {-year OS } 82 \% \text {; } \\
5 \text {-year CSS } 100 \%^{\text {b }} \text {; } 5 \text {-year } \\
\text { OS } 92 \%^{\text {b }}\end{array}$ \\
\hline
\end{tabular}

$\mathrm{BCR}=$ Biochemical recurrence; $\mathrm{LN}=$ total $\mathrm{LNs} ; \mathrm{N}+=\mathrm{LN}$ metastases; $\mathrm{SLN}+=\mathrm{SLN}$ metastases; $\mathrm{NA}=$ not available. ${ }^{\mathrm{a}}$ Median value. ${ }^{\mathrm{b}}$ Patients with merely micrometastases.

$[24,25]$. Thus, if PLND is indicated in intermediate- and especially high-risk patients, some urological associations and authors recommend the extended technique [26]. In this regard, the study published by Weight et al. [27] indicates that IPLND may not be necessary in patients with low-risk PCa, without any negative effect on patient outcome.

Studies on SLND have reported that the combination of SLND and ePLND may improve RFS $[5,6,14,28]$, and our results confirm this finding. Additionally, some authors have suggested a benefit in terms of RFS following the combination of RRP and ePLND [1, 2, 6, 11, 14, 17]. Concerning intermediate- and high-risk patients, Schiavina et al. [17] confirmed the positive effect of ePLND on RFS due to the removal of micrometastases despite critical tumor characteristics.

The results of Mattei et al. [25] indicate that one-third of all LN metastases are missed even using ePLND, as $16 \%$ of the nodes are localized along the common iliac vessels,
$8 \%$ in the presacral/pararectal region, and $12 \%$ along the aorta and vena cava. According to our results, as mentioned in table 1 and figure 3, patients with intermediaterisk PCa should undergo eSLND. A curative approach would not otherwise have been available to this subgroup of patients, and adequate PLND therefore appears mandatory for high-risk patients as well as this intermediaterisk group.

Compared with previous ePLND studies, our survival rates in the RRP study population after eSLND confirmed a reasonable benefit from this procedure (table 5). However, the treatment of our heterogeneous study cohort is debatable in regard to short-term preoperative neoadjuvant $\mathrm{AD}$. Thus, it is possible that micrometastases may not have been detected histopathologically in some of our patients due to induced regression. Additionally, the total nodal count was lower than in the ePLND series of Bader et al. [1] and Schumacher et al. [18], possibly due to their complex procedure for histopathological analysis. 
The heterogeneity of the study population is also debatable in regard to adjuvant therapeutic procedures. This limitation applies to our $\mathrm{pN} 1$ study population as well as the literature group referenced in table 5. Although a direct comparison is difficult, the survival rates reported in the studies by Bader et al. [1], Allaf et al. [2], and Fleischmann et al. [15], in which patients received neither neoadjuvant nor adjuvant therapy immediately after surgery, were compared in table 5. In our study, patients with mere micrometastases presented similar results, if not improved results, for 5-year RFS, 5-year CSS, and 5-year OS (table 5), and studies containing heterogeneous patient groups $[10,18,29]$ reported comparable postoperative survival rates (table 5).

With the restriction that this study was clearly retrospective, the data presented above support the importance of eSLND for accurate staging and carcinoma-specific outcome, specifically in regard to intermediate-risk patients.

\section{Conclusion}

Of note, our results showed that 53 patients with a low nodal tumor burden and mere evidence of micrometastases showed long-term RFS, presenting a mean RFS of 6.2 years and a mean CSS of 9.9 years. However, this result will be difficult to achieve without the routine clinical adoption of eSLND. Thus, ePLND in combination with RRP should not be withheld from patients with intermediate- or high-risk PCa, particularly if a potential curative approach is discussed. A valid alternative to ePLND may be eSLND, as their results are similar if performed routinely and frequently.

\section{Acknowledgements}

We are grateful to all attending urologists and physicians as well as to all members of the Prostatazentrum Hochfranken-Fichtelgebirge for supporting us in completing the follow-up data on the patients. The following individuals have contributed relevant data to this study: M. Mugler, S. Kribus, C. Seidl, and M. Sachs, Partnerschaft Pathologie, Hof, and K.-F. Wurm, K. Maag, and R. Schaffhauser, Abteilung für Nuklearmedizin, Klinikum Fichtelgebirge.

\section{References}

1 Bader P, Burkhard FC, Markwalder R, Studer UE: Disease progression and survival of patients with positive lymph nodes after radical prostatectomy. Is there a chance of cure? J Urol 2003;169:849-854.

2 Allaf ME, Palapattu GS, Trock BJ, Carter HB, Walsh PC: Anatomical extent of lymph node dissection: impact on men with clinically localized prostate cancer. J Urol 2004;172: $1840-1844$

-3 Wawroschek F, Vogt H, Wengenmair H, Weckermann D, Hamm M, Keil M, Graf G, Heidenreich P, Harzmann R: Prostate lymphoscintigraphy and radio-guided surgery for sentinel lymph node identification in prostate cancer. Technique and results of the first 350 cases. Urol Int 2003;70:303-310.

4 Weckermann D, Goppelt M, Dorn R, Wawroschek F, Harzmann R: Incidence of positive pelvic lymph nodes in patients with prostate cancer, a prostate-specific antigen (PSA) level of $\leq 10 \mathrm{ng} / \mathrm{ml}$ and biopsy Gleason-Score of $\leq 6$, and their influence on PSA progressionfree survival after radical prostatectomy. BJU Int 2006;97:1173-1178.

5 Bastide C, Brenot-Rossi I, Garcia S, Rossi D: Radioisotope guided sentinel lymph node dissection in patients with localized prostate cancer: results of the first 100 cases. Eur J Surg Oncol 2009;35:751-756.
6 Weckermann D, Dorn R, Trefz M, Wagner T, Wawroschek F, Harzmann R: Sentinel lymph node dissection for prostate cancer: experience with more than 1,000 patients. J Urol 2007;177:916-920.

-7 Cai T, Nesi G, Tinacci G, Giubilei G, Gavazzi A, Mondaini N, Zini E, Bartoletti R: Clinical importance of lymph node density in predicting outcome of prostate cancer patients. J Surg Res 2011;167:267-272.

-8 Heidenreich A, Ohlmann $\mathrm{CH}$, Polyakov S: Anatomical extent of pelvic lymphadenectomy in patients undergoing radical prostatectomy. Eur Urol 2007;52:29-37.

-9 Wagner M, Sokoloff M, Daneshmand S: The role of pelvic lymphadenectomy for prostate cancer - therapeutic? J Urol 2008;179:408413.

10 Daneshmand S, Quek ML, Stein JP, Lieskovsky G, Cai J, Pinski J, Skinner EC, Skinner DG: Prognosis of patients with lymph node positive prostate cancer following radical prostatectomy: long-term results. J Urol 2004; 172:2252-2255

11 Joslyn SA, Konety BR: Impact of extent of lymphadenectomy on survival after radical prostatectomy for prostate cancer. Urology 2006;68:121-125.
12 Clark T, Parekh DJ, Cookson MS, Chang SS Smith ER Jr, Wells N, Smith JA Jr: Randomized prospective evaluation of extended versus limited lymph node dissection in patients with clinically localized prostate cancer. J Urol 2003;169:145-148.

13 Murphy AM, Berkman DS, Desai M, Benson MC, McKiernan JM, Badani KK: The number of negative pelvic lymph nodes removed does not affect the risk of biochemical failure after radical prostatectomy. BJU Int 2010;105:176179.

14 Weckermann D, Dorn R, Holl G, Wagner T, Harzmann R: Limitations of radioguided surgery in high-risk prostate cancer. Eur Urol 2007;51:1549-1558.

15 Fleischmann A, Schobinger S, Schumacher M, Thalmann GN, Studer UE: Survival in surgically treated, nodal positive prostate cancer patients is predicted by histopathological characteristics of the primary tumor and its lymph node metastases. Prostate 2009;69: 352-362.

16 Palapattu GS, Allaf ME, Trock BJ, Epstein JI, Walsh PC: Prostate specific antigen progression in men with lymph node metastases following radical prostatectomy: results of longterm followup. J Urol 2004;172:1860-1864. 
17 Schiavina R, Manferrari F, Garofalo M, Bertaccini A, Vagnoni V, Guidi M, Borghesi M, Baccos A, Morselli-Labate AM, Concetti S, Martorana G: The extent of pelvic lymph node dissection correlates with the biochemical recurrence rate in patients with intermediate- and high-risk prostate cancer. BJU Int 2011;108:1262-1268.

18 Schumacher MC, Burkhard FC, Thalmann GN, Fleischmann A, Studer UE: Good outcome for patients with few lymph node metastases after radical retropubic prostatectomy. Eur Urol 2008;54:344-352.

19 Boorjian SA, Thompson RH, Siddiqui S, Bagniewski S, Bergstralh EJ, Karnes RJ, Frank I, Blute ML: Long-term outcome after radical prostatectomy for patients with lymph node positive prostate cancer in the prostate specific antigen era. J Urol 2007;178:864-871.

20 Xiao WJ, Ye DW, Yao XD, Zhang SL, Dai B: Comparison of three versions of Partin tables to predict final pathologic stage in a Chinese cohort: a decision curve analysis. Urol Int 2013;91:69-74.

21 Froehner M, Novotny V, Koch R, Leike S, Twelker L, Wirth MP: Perioperative complications after radical prostatectomy: open versus robot-assisted laparoscopic approach. Urol Int 2013;90:312-315.
22 Mearini L, Gacci M, Saleh O, De Nunzio C, Schiavina R, Simonato A, Tubaro A, Carmignani G, Mirone V, Carini M, Bini V, Porena M: External validation of nomogram predicting the probability of specimen-confined disease (pT2-3a, R0N0) in patients undergoing radical prostatectomy and pelvic lymph node dissection. Urol Int DOI: 10.1159/000354430.

23 Briganti A, Capitanio U, Chun FKH, Gallina A, Suardi N, Salonia A, da Pozzo LF, Colombo R, di Girolamo V, Bertini R, Guazzoni G, Karakiewicz PI, Montorsi F, Rigatti P: Impact of surgical volume on the rate of lymph node metastases in patients undergoing radical prostatectomy and extended pelvic lymph node dissection for clinically localized prostate cancer. Eur Urol 2008;54:794-802.

24 Jeschke S, Beri A, Grüll M, Ziegerhofer J, Prammer P, Leeb K, Sega W, Janetschek G: Laparoscopic radioisotope-guided sentinel lymph node dissection in staging of prostate cancer. Eur Urol 2008;53:126-133.
25 Mattei A, Fuechsel FG, Bhatta Dhar N, Warncke SH, Thalmann GN, Krause T, Studer UE: The template of the primary lymphatic landing sites of the prostate should be revisited: results of a multimodality mapping study. Eur Urol 2008;53:118-125.

26 Briganti A, Blute ML, Eastham JH, Graefen M, Heidenreich A, Karnes JR, Montorsi F, Studer UE: Pelvic lymph node dissection in prostate cancer. Eur Urol 2009;55:1251-1265.

27 Weight CJ, Reuther AM, Gunn PW, Zippe CR, Dhar NB, Klein EA: Limited pelvic lymph node dissection does not improve biochemical relapse free survival at 10 years after radical prostatectomy in patients with low-risk prostate cancer. Urology 2008;71:141-145.

28 Hautmann S, Beitz S, Naumann M, Lützen U, Stübinger SH, van der Horst C, Braun PM, Leuschner I, Henze E, Jünemann EH: Die extendierte Sentinel-Lymphadenektomie im Rahmen der radikalen Prostatektomie? Untersuchungen im Kieler Risikokollektiv. Urologe A 2008;47:299-303.

-29 Engel J, Bastian PJ, Baur H, Beer V, Chaussy C, Gschwend JE, Oberneder R, Rothenberger KH, Stief CG, Hölzel D: Survival benefit of radical prostatectomy in lymph node-positive patients with prostate cancer. Eur Urol 2010; 57:754-761. 